\title{
An overview of rheumatological research in the European Union
}

\author{
Giuseppe S Mela, Marco A Cimmino
}

\begin{abstract}
Objectives-To evaluate the distribution and scope of papers published by authors from the European Union (EU) in rheumatological journals and the impact of rheumatological research in the $E U$ in comparison with that produced elsewhere.

Methods-Papers published during the year 1995 in the 17 rheumatological journals screened by ISI were considered. The journal impact factor (IF) was noted. All key words, both those reported by the authors and those attributed by ISI, were identified and their frequency was calculated using a special purpose program.

Results-2331 papers were published in the rheumatological literature during 1995. Of them, $1316(56.5 \%)$ came from the EU $29.4 \%$ from the UK, $17.4 \%$ from France, $11.5 \%$ from Germany, and $10.8 \%$ from Italy) and $544(23.3 \%)$ from the USA. The mean IF of EU papers was approximately 2 in comparison with 3.5 for the USA and 2.4 for other countries. In 1995, 2680 key words attributed by the authors and 5651 attributed by ISI appeared in the rheumatological literature. Less than a quarter of them was cited more than twice. The leading key words were rheumatoid arthritis for diseases and methotrexate for drugs.

Conclusions-Bibliometric findings are useful to follow research trends. These data show the relevance of EU rheumatological research and the high scientific production of small countries. Dispersion of key words should be avoided and journal editors should promote their standardisation.

(Ann Rheum Dis 1998;57:643-647)
\end{abstract}

In the countries of the European Union (EU), funding for research is increasingly shifting from a national to an international basis. The value of European research as compared with that of other leading countries could represent a useful piece of information and help increase the confidence of European researchers in applying for international grants. Quantification of the relative contribution to scientific advancement in rheumatology of the European countries is lacking. Although USA and UK are widely perceived as the main sources of scientific production, Benzer et $a l^{1}$ have shown that small countries, such as Israel, Sweden, Switzerland, Denmark, and the Netherlands, have a high number of medical publications per million inhabitants. The figures for 1990 were higher than those for the UK and USA.

We performed an analysis of papers published in 1995 in the 17 journals considered as pertinent to rheumatology by the Institute for Scientific Information (ISI) and correlated them with the source country population and its gross domestic product (GDP). The impact factor (IF) of the journal of publication was considered an indirect estimate of scientific quality of the paper. To gain an insight of the major fields of research, we also investigated the frequency of keywords in the rheumatological literature.

\section{Methods}

The following is a list of the rheumatological periodicals considered with their IF for 1995: Aktuelle Rheumatologie (0.11), Annals of the Rheumatic Diseases (2.63), Arthritis and Rheumatism (7.23), Bailliere's Clinical Rheumatology (0.52), British fournal of Rheumatology (2.22), Bulletin on the Rheumatic Diseases (0.63), Clinical Rheumatology (0.56), Clinical and Experimental Rheumatology (0.99), fournal of Rheumatology (2.24), Osteoarthritis and Cartilage (no IF attributed in 1995), Osteoporosis International (2.91), Revue du Rhumatisme (0.62), Rheumatic Diseases Clinics of North America (2.44), Rheumatology International (1.18), Scandinavian Fournal of Rheumatology (1.21), Seminars in Arthritis and Rheumatism (1.77), and Zeitschrift für Rheumatolgie (0.52).

Bibliographic data were downloaded from Current Contents/Life Science and Current Contents/Clinical Medicine (1995-1997 actual years). Only bibliographic items with ISSN and nominal edition year 1995 were selected. Duplicate items were identified and deleted. For the purpose of this study, the definition of EU includes the 15 countries belonging to the EU plus Norway. Norway was included because it is a member of the European Economic Area (EEA). In addition, the Statistical Office of the European Communities (Eurostat) includes Norway in all its calculations concerning the EU. ${ }^{2}$ The country of 
Table 1 Comparison of the scientific production of different countries

\begin{tabular}{|c|c|c|c|c|c|c|c|c|c|c|c|c|}
\hline \multirow[b]{2}{*}{ Country } & \multicolumn{5}{|c|}{ Rheumatological journals } & \multicolumn{5}{|c|}{ All medical journals } & \multirow[b]{2}{*}{$\begin{array}{l}\% \text { Rheum } \\
\text { papers }\end{array}$} & \multirow[b]{2}{*}{$\begin{array}{l}\text { IF ratio } \\
\text { rheum/ all }\end{array}$} \\
\hline & $\begin{array}{l}\text { Number } \\
\text { of papers }\end{array}$ & $\begin{array}{l}\% \\
(U E=100)\end{array}$ & $\begin{array}{l}\text { Mean } \\
\text { IF }\end{array}$ & $\begin{array}{l}\text { Papers/ } \\
G D P\end{array}$ & $\begin{array}{l}\text { Papers/ } \\
\text { million } \\
\text { population }\end{array}$ & $\begin{array}{l}\text { Number of } \\
\text { papers }\end{array}$ & $\begin{array}{l}\% \\
(U E=100)\end{array}$ & $\begin{array}{l}\text { Mean } \\
\text { IF }\end{array}$ & $\begin{array}{l}\text { Papers/ } \\
G D P\end{array}$ & $\begin{array}{l}\text { Papers/ } \\
\text { million } \\
\text { population }\end{array}$ & & \\
\hline Austria & 16 & 1.2 & 3.7 & 0.08 & 1.9 & 2165 & 1.9 & 2.6 & 11.6 & 270.1 & 0.7 & 1.4 \\
\hline Belgium & 38 & 2.9 & 1.4 & 0.18 & 3.8 & 3367 & 2.9 & 2.6 & 15.9 & 337.4 & 1.1 & 0.5 \\
\hline Denmark & 26 & 2.0 & 1.8 & 0.19 & 5.0 & 2893 & 2.5 & 2.4 & 21.2 & 562.1 & 0.9 & 0.8 \\
\hline Finland & 51 & 3.9 & 2.1 & 0.53 & 10.2 & 2700 & 2.3 & 2.5 & 28.4 & 540.2 & 1.9 & 0.8 \\
\hline France & 229 & 17.4 & 1.6 & 0.18 & 4.0 & 17325 & 14.9 & 2.5 & 13.6 & 306.0 & 1.3 & 0.6 \\
\hline Germany & 151 & 11.5 & 1.6 & 0.07 & 1.8 & 20314 & 17.5 & 2.5 & 10.6 & 249.7 & 0.7 & 0.6 \\
\hline Greece & 12 & 0.9 & 2.0 & 0.15 & 1.1 & 985 & 0.8 & 1.6 & 12.9 & 95.9 & 1.2 & 1.3 \\
\hline Ireland & 7 & 0.5 & 2.8 & 0.15 & 1.9 & 821 & 0.7 & 2.1 & 18.5 & 232.8 & 0.9 & 1.3 \\
\hline Italy & 142 & 10.8 & 1.6 & 0.12 & 2.4 & 11238 & 9.7 & 2.4 & 9.5 & 196.6 & 1.3 & 0.7 \\
\hline Luxembourg & 0 & 0.0 & 0.0 & 0.00 & 0.0 & 15 & 0.0 & 4.8 & 1.0 & 38.9 & 0.0 & 0.0 \\
\hline Netherlands & 99 & 7.5 & 2.3 & 0.31 & 6.5 & 7535 & 6.5 & 3.0 & 24.0 & 498.0 & 1.3 & 0.8 \\
\hline Norway & 24 & 1.8 & 1.7 & 0.21 & 5.5 & 1666 & 1.4 & 2.2 & 14.7 & 387.5 & 1.4 & 0.8 \\
\hline Portugal & 6 & 0.5 & 1.3 & 0.07 & 0.6 & 390 & 0.3 & 2.0 & 5.0 & 39.5 & 1.5 & 0.7 \\
\hline Spain & 75 & 5.7 & 2.0 & 0.14 & 1.9 & 6534 & 5.6 & 2.2 & 12.3 & 168.6 & 1.2 & 0.9 \\
\hline Sweden & 53 & 4.0 & 2.1 & 0.24 & 6.0 & 6321 & 5.4 & 2.4 & 29.2 & 727.2 & 0.8 & 0.9 \\
\hline United Kingdom & 387 & 29.4 & 2.4 & 0.37 & 6.6 & 31921 & 27.5 & 3.5 & 30.5 & 548.5 & 1.2 & 0.7 \\
\hline EU & 1316 & 100.0 & 2.0 & 0.17 & 3.5 & 116190 & 100.0 & 2.8 & 15.6 & 312.0 & 1.1 & 0.7 \\
\hline Australia & 55 & 4.2 & 2.7 & 0.17 & 3.1 & 7202 & 6.2 & 2.6 & 23.3 & 408.6 & 0.8 & 1.0 \\
\hline Canada & 138 & 10.5 & 2.6 & 0.24 & 5.0 & 12316 & 10.6 & 3.0 & 21.8 & 451.1 & 1.1 & 0.9 \\
\hline Israel & 27 & 2.1 & 2.5 & 0.38 & 5.3 & 3019 & 2.6 & 2.8 & 43.3 & 596.7 & 0.9 & 0.9 \\
\hline Japan & 69 & 5.2 & 2.9 & 0.01 & 0.5 & 23130 & 19.9 & 2.4 & 5.9 & 185.8 & 0.3 & 1.2 \\
\hline Mexico & 23 & 1.7 & 2.7 & 0.07 & 0.2 & 748 & 0.6 & 1.7 & 2.4 & 9.2 & 3.1 & 1.6 \\
\hline Switzerland & 36 & 2.7 & 2.0 & 0.14 & 5.1 & 4634 & 4.0 & 3.2 & 18.2 & 664.9 & 0.8 & 0.6 \\
\hline USA & 544 & 41.3 & 3.5 & 0.08 & 2.0 & 118482 & 102.0 & 3.9 & 18.3 & 454.4 & 0.5 & 0.9 \\
\hline World & 2331 & 177.1 & 2.4 & 0.09 & 0.4 & 309501 & 266.4 & 3.1 & 12.8 & 62.0 & 0.8 & 0.8 \\
\hline
\end{tabular}

$\mathrm{IF}=$ impact factor, $\mathrm{GDP}=$ gross domestic product in billion US dollars

the corresponding author was considered as the country of origin of the article. The papers from England, Scotland, Northern Ireland, and Wales were grouped under the United Kingdom (UK) heading. For comparison, data on seven additional countries, each showing more than 20 entries in the above listed journals during 1995, were also considered. On occasion, it was necessary to manually identify the country source of a given article after consulting other bibliographic databases. The country of origin of $3 \%$ of the articles, mainly editorials, remained unknown because of lack of specific data.

All peer reviewed papers, including editorials, reviews, technical notes and letters to the editor were considered. Journal supplements containing abstracts or meeting reports were excluded.

For the purpose of our study, keywords were defined as comma separated items of one or more words. All keywords, both those reported by the authors and those attributed by ISI, were identified and their frequency was calculated in two separate files using a special purpose program. Different keywords with identical meaning were grouped and considered as a single keyword. The same process was used for misspelled key words.

The resident population and GDP expressed in current billion US dollars for 1995 were retrieved for each country from the Eurostat annual statistic review. ${ }^{2}$ Updated data are shown on the internet site www.cilnews.unige.it.

\section{Results}

NUMBER OF PAPERS

A total of 2331 papers were published in the rheumatological literature during 1995 (table 1). Of them, 1316 (56.5\%) came from the EU and $544(23.3 \%)$ from the USA. All EU countries were represented except Luxembourg.
The leading countries were the UK $(29.4 \%$ of papers), France (17.4\%), Germany (11.5\%), and Italy $(10.8 \%)$. For comparison purposes, a total of 309501 papers were published in the world medical literature during the same year. Of them, $116190(37.5 \%)$ were from the EU and $118482(38.3 \%)$ from the USA. Their breakdown within the EU countries was similar to that of rheumatological papers, with Germany reaching second place. Rheumatological papers accounted for $1.1 \%$ of the total number of medical papers (table 1). In the USA, the percentage of rheumatological papers was lower $(0.46 \%)$. The ratio of rheumatological papers was higher in Finland and Mexico, with $1.89 \%$ and $3.07 \%$ of the total number of medical papers, respectively.

FREQUENCY OF PUBLICATION BY JOURNAL AND SOURCE COUNTRY

Table 2 shows the percentage of papers by country of origin for each journal. The Bulletin of the Rheumatic Diseases contained no papers from EU authors; Rheumatic Diseases Clinics of North America and Seminars in Arthritis and Rheumatism had only $12 \%$ and $19 \%$ of the papers from the EU, respectively. The remaining 14 journals had a frequency of EU papers ranging between $30 \%$ and $91 \%$.

Journals that published a high number of papers from authors outside their country of publication included Clinical Rheumatology (published in Belgium), Rheumatology International (Germany), fournal of Rheumatology (Canada), and Clinical and Experimental Rheumatology (Italy). Most authors of the papers published in the Revue du Rhumatisme (France), Aktuelle Rheumatologie (Germany), Zeitschrift für Rheumatologie (Germany), Bulletin on the Rheumatic Diseases (USA), and Rheumatic Disease Clinics of North America (USA) were from the relevant country. 
Table 2 Percentage of papers published in each journal according to the country of origin of the corresponding author

\begin{tabular}{|c|c|c|c|c|c|c|c|c|c|c|c|c|}
\hline fournal & Austria & Belgium & Denmark & Finland & France & Germany & Greece & Ireland & Italy & Luxembourg & Netherlands & Norway \\
\hline Aktuel Rheumatol & 1.6 & 0.0 & 0.0 & 0.0 & 0.0 & 68.9 & 0.0 & 0.0 & 0.0 & 0.0 & 0.0 & 0.0 \\
\hline Ann Rheum Dis & 0.0 & 0.8 & 0.4 & 3.6 & 5.6 & 4.8 & 0.4 & 0.8 & 3.2 & 0.0 & 4.8 & 0.8 \\
\hline Arthritis Rheum & 2.3 & 0.3 & 0.0 & 1.2 & 4.1 & 4.9 & 0.3 & 0.6 & 2.0 & 0.0 & 2.9 & 0.0 \\
\hline Bailliere Clin Rheum & 0.0 & 0.0 & 0.0 & 0.0 & 0.0 & 1.8 & 0.0 & 0.0 & 1.8 & 0.0 & 5.3 & 0.0 \\
\hline Brit J Rheumatol & 0.9 & 0.9 & 1.5 & 2.4 & 6.5 & 0.9 & 0.3 & 0.6 & 1.2 & 0.0 & 4.8 & 0.9 \\
\hline B Rheum Dis & 0.0 & 0.0 & 0.0 & 0.0 & 0.0 & 0.0 & 0.0 & 0.0 & 0.0 & 0.0 & 0.0 & 0.0 \\
\hline Clin Exp Rheumatol & 1.2 & 1.2 & 1.6 & 4.1 & 11.5 & 2.5 & 2.9 & 0.0 & 32.0 & 0.0 & 2.5 & 2.1 \\
\hline Clin Rheumatol & 0.7 & 13.6 & 1.4 & 0.7 & 6.1 & 2.0 & 2.7 & 1.4 & 12.9 & 0.0 & 6.1 & 1.4 \\
\hline J Rheumatol & 0.6 & 1.1 & 0.6 & 1.1 & 5.9 & 2.1 & 0.4 & 0.1 & 3.7 & 0.0 & 5.3 & 1.0 \\
\hline Osteoarthr Cartil & 0.0 & 2.9 & 0.0 & 0.0 & 8.8 & 0.0 & 0.0 & 0.0 & 0.0 & 0.0 & 5.9 & 0.0 \\
\hline Osteoporosis Int & 0.0 & 2.9 & 7.1 & 0.0 & 15.7 & 1.4 & 0.0 & 0.0 & 10.0 & 0.0 & 1.4 & 1.4 \\
\hline Rev Rhum (Fr Ed) & 0.0 & 2.1 & 0.0 & 0.0 & 78.4 & 0.0 & 0.0 & 0.0 & 0.0 & 0.0 & 0.0 & 0.0 \\
\hline Rev Rhum (Eng Ed) & 0.0 & 0.0 & 0.0 & 0.0 & 80.7 & 0.0 & 0.0 & 0.0 & 1.8 & 0.0 & 0.0 & 0.0 \\
\hline Rheum Dis Clin N Am & 0.0 & 0.0 & 0.0 & 0.0 & 3.4 & 3.4 & 0.0 & 0.0 & 0.0 & 0.0 & 0.0 & 0.0 \\
\hline Rheumatol Int & 0.0 & 0.0 & 0.0 & 2.2 & 2.2 & 19.6 & 2.2 & 0.0 & 15.2 & 0.0 & 4.4 & 0.0 \\
\hline Scand J Rheumatol & 0.0 & 0.7 & 4.4 & 12.6 & 3.7 & 9.6 & 0.0 & 0.0 & 1.5 & 0.0 & 13.3 & 5.2 \\
\hline Semin Arthritis Rheum & 0.0 & 0.0 & 0.0 & 2.7 & 0.0 & 0.0 & 0.0 & 0.0 & 0.0 & 0.0 & 2.7 & 0.0 \\
\hline Z Rheumatol & 1.9 & 0.0 & 0.0 & 0.0 & 0.0 & 77.4 & 0.0 & 0.0 & 0.0 & 0.0 & 0.0 & 0.0 \\
\hline
\end{tabular}

QUALITY OF PAPERS

The mean impact factor (IF) of papers from the EU in rheumatological journals was nearly 2 in comparison with 3.5 for the USA (table 1). The world IF for rheumatological papers was 2.4. Among EU nations, Austria ranked first with a mean IF of 3.7, followed by Ireland (2.8), the UK (2.4), Netherlands (2.3), Finland (2.1), and Sweden (2. 1). The mean IF in other non-EU countries ranged from 2 for Switzerland to 2.9 for Japan. The mean IF of the whole medical literature produced in the EU was higher (2.8) than that of rheumatological papers. Luxembourg (4.8), UK (3.5), and Netherlands (3) had particularly high whole medical literature IFs. In non-EU countries, rheumatological and medical IFs were similar, with the exception of Mexico. The ratio between the IFs of rheumatological journals and the whole medical literature was calculated. A value exceeding 1, indicating that in a given country rheumatological papers reached a higher IF than the remaining medical literature, was shown by Austria (1.42), Ireland (1.33), Greece (1.25), Mexico (1.59), and Japan (1.21).

SCIENTIFIC PRODUCTION VIS A VIS GDP AND POPULATION

The ratio between number of rheumatological papers and GDP showed a mean value of 0.178 for the EU, a value that compares favourably with that of 0.084 calculated for the USA (table 1). In the EU, Finland ranked first (0.538), followed by the UK (0.370) and Netherlands (0.316). When all the medical scientific literature was considered, the USA scored better than the EU (18.3 v 15.6). The UK (30.5), Sweden (29.2), Finland (28.4), and Netherlands (24) showed the highest values in

Table 3 Number of citations of the 10 most cited rheumatological diseases with their mean impact factor

\begin{tabular}{llll}
\hline Rank & Disease & Number & Mean IF \\
\hline 1 & Rheumatoid arthritis & 247 & 2.61 \\
2 & Systemic lupus erythematosus & 130 & 2.76 \\
3 & Osteoarthritis & 107 & 3.08 \\
4 & Scleroderma & 55 & 2.78 \\
5 & Fybromyalgia & 32 & 2.83 \\
6 & Reactive arthritis & 31 & 2.56 \\
7 & Sjögren's syndrome & 31 & 2.32 \\
8 & Polymyositis/dermatomyositis & 29 & 3.77 \\
9 & Juvenile rheumatoid arthritis & 29 & 2.31 \\
10 & Ankylosing spondylitis & 25 & 2.38 \\
\hline
\end{tabular}

the EU. The highest value belonged to Israel, with 43.4 papers/billion US dollars of GDP.

The ratio between number of rheumatological papers and country population in millions of inhabitants was 3.5 for the EU and 2.1 for the USA (table 1). In Europe, small countries generally performed better than large ones. Finland ranked first with the best world score (10.2) followed by the UK (6.6), Netherlands (6.5), Sweden (6. 1), Norway (5.6), and Denmark (5.0). Outside the EU, high scores were seen for Israel (5.3), Switzerland (5.2), and Canada (5. 1). The analysis of the world medical literature per country population yielded values of 312.1 in the EU and of 454.5 in the USA. The EU highest scores were those of Sweden (727.2), Denmark (562.2), the UK (548.6), and Finland (540.2). Switzerland (664.9) and Israel (596.7) ranked high among non-EU countries.

RESEARCH TOPICS IN THE RHEUMATOLOGICAL LITERATURE

In rheumatological journals, the keywords attributed by the authors comprised as many as 2680 different items. Of them, only 438 were cited more than twice and 57 were cited more than 10 times. A total of 5651 keywords attributed by ISI appeared in the rheumatological literature. Of them, 1147 were cited more than twice and 247 more than 10 times. Misspelled or non-standardised key words were found frequently. As an example, cyclosporine A was present with four different forms (cyclosporine, cyclosporine A, cyclosporyn, cyclosporin A); the same happened with osteoarthritis (osteo arthritis, osteoarthritis, osteoarthrosis, arthrosis). The top 10 keywords attributed by authors related to disease types are listed in table 3 and those related to drug types are listed in table 4.

Table 4 Number of citations of the 10 most cited drugs or drug classes with their mean impact factor

\begin{tabular}{llll}
\hline Rank & Drug & Number & Mean IF \\
\hline 1 & Methotrexate & 56 & 3.26 \\
2 & Corticosteroids & 28 & 3.19 \\
3 & Gold salts & 14 & 3.21 \\
4 & Sulphasalazine & 8 & 4.26 \\
5 & Diphosphonate & 8 & 5.07 \\
6 & Cyclosporine & 7 & 2.77 \\
7 & Indomethacin & 6 & 2.24 \\
8 & Cyclophosphamide & 5 & 4.31 \\
9 & Calcium & 5 & 2.89 \\
10 & Vitamin D & 4 & 1.61 \\
\hline
\end{tabular}


Table 2 continued

\begin{tabular}{|c|c|c|c|c|c|c|c|c|c|c|c|c|}
\hline Portugal & Spain & Sweden & United Kingdom & $E U$ & Australia & Canada & Israel & fapan & Mexico & Switzerland & $U S A$ & Other Countries \\
\hline 0.0 & 0.0 & 0.0 & 3.3 & 73.8 & 0.0 & 0.0 & 0.0 & 0.0 & 0.0 & 3.3 & 0.0 & 23.0 \\
\hline 0.4 & 4.4 & 2.0 & 37.8 & 69.9 & 3.2 & 2.4 & 0.0 & 5.2 & 0.0 & 2.4 & 8.4 & 8.4 \\
\hline 0.0 & 0.6 & 1.5 & 9.6 & 30.2 & 2.0 & 4.4 & 1.2 & 4.1 & 2.3 & 1.2 & 49.6 & 5.2 \\
\hline 0.0 & 0.0 & 1.8 & 45.6 & 56.1 & 7.0 & 1.8 & 0.0 & 0.0 & 0.0 & 0.0 & 17.5 & 17.5 \\
\hline 0.0 & 5.9 & 1.5 & 45.4 & 73.6 & 3.0 & 2.1 & 0.3 & 3.0 & 0.6 & 0.6 & 6.5 & 10.4 \\
\hline 0.0 & 0.0 & 0.0 & 0.0 & 0.0 & 0.0 & 0.0 & 0.0 & 0.0 & 0.0 & 0.0 & 94.7 & 5.3 \\
\hline 0.4 & 3.7 & 3.3 & 9.4 & 78.3 & 0.0 & 0.8 & 2.5 & 3.3 & 2.1 & 0.8 & 6.6 & 5.7 \\
\hline 2.0 & 4.1 & 1.4 & 7.5 & 63.9 & 0.0 & 1.4 & 4.1 & 6.1 & 0.0 & 2.7 & 4.1 & 17.7 \\
\hline 0.1 & 3.6 & 1.7 & 7.1 & 34.6 & 3.0 & 15.4 & 1.7 & 2.9 & 1.6 & 1.1 & 34.4 & 5.3 \\
\hline 0.0 & 0.0 & 5.9 & 20.6 & 44.1 & 5.9 & 11.8 & 0.0 & 2.9 & 0.0 & 0.0 & 26.5 & 8.82 \\
\hline 0.0 & 0.0 & 2.9 & 11.4 & 54.3 & 2.9 & 2.9 & 0.0 & 0.0 & 0.0 & 4.3 & 30.0 & 5.7 \\
\hline 0.0 & 1.0 & 0.0 & 6.2 & 87.6 & 0.0 & 1.0 & 1.0 & 0.0 & 0.0 & 0.0 & 1.0 & 9.3 \\
\hline 0.0 & 7.0 & 0.0 & 1.8 & 91.2 & 0.0 & 0.0 & 0.0 & 0.0 & 1.8 & 1.8 & 0.0 & 5.3 \\
\hline 0.0 & 0.0 & 1.7 & 3.4 & 11.9 & 1.7 & 3.4 & 0.0 & 0.0 & 0.0 & 0.0 & 83.1 & 0.0 \\
\hline 0.0 & 4.4 & 0.0 & 10.9 & 60.9 & 8.7 & 2.2 & 2.2 & 6.5 & 2.2 & 4.4 & 4.4 & 8.7 \\
\hline 0.0 & 1.5 & 10.4 & 5.2 & 68.1 & 0.0 & 1.5 & 0.0 & 4.4 & 0.7 & 0.0 & 8.2 & 17.0 \\
\hline 0.0 & 5.4 & 0.0 & 8.1 & 18.9 & 0.0 & 8.1 & 13.5 & 0.0 & 0.0 & 2.7 & 54.1 & 2.7 \\
\hline 0.0 & 0.0 & 0.0 & 1.9 & 81.1 & 0.0 & 0.0 & 0.0 & 0.0 & 0.0 & 13.2 & 0.0 & 5.7 \\
\hline
\end{tabular}

\section{Discussion}

Our data show that the geographical composition of the rheumatological literature had scarcely changed in comparison with the values reported in 1987 by Ruiz et al. ${ }^{3}$ The only remarkable exception was the increase in number of foreign papers published by the UK journals British fournal of Rheumatology $(+21.4 \%)$ and Annals of The Rheumatic Diseases $(+6.9 \%)$.

Rheumatological journals usually publish articles in the English language, except for the Zeitschrift für Rheumatologie (mostly German), Aktuelle Rheumatologie (German), and Revue du Rhumatisme (French). Beginning in January 1993, Revue du Rhumatisme has also started an English edition, which publishes more than $80 \%$ of articles from French authors. The language preference of these journals may represent a bias in our comparative estimate of rheumatological literature production. On the one hand, German and French authors may find it easier to publish in these journals; on the other hand they may be less prone to submit their papers to English language journals of greater international competition.

A corollary observation is that Germany and France, which have a strong tradition of scientific publication in their own languages, may be penalised in comparative studies relying on databases that include few non-English language journals. For example, EMBASE includes more non-English-language journals than MEDLINE. ${ }^{4}$ None the less, English has become the common language of the scientific community and future bibliometric studies are likely to be performed only on English journals.

The rheumatological scientific production in the EU was more than twice that of the USA in terms of number of papers despite a large difference in research fundings available across the Atlantic. In addition, the percentage of rheumatological papers within the medical literature was also higher in the EU than in the USA. This finding confirms that the EU, which is becoming even more integrated, has a leading role in rheumatological research. However, the mean IF of rheumatological papers was higher in the USA than in the EU. This could be because American journals in the rheumatological field are few and have a high IF. In Europe, there are many national journals and competition for publication is lower. An international European journal could probably reach a higher IF than those of the national journals.

In 1995, authors from each EC country, except Luxembourg, published papers in the rheumatological journals. Large countries, such as the UK, France, Germany, and Italy ranked at the top four places for absolute number of papers. Ranking considerably changed when other variables, such as mean impact factor, number of papers per inhabitants, or number of papers for GPD, were considered. Austria and Ireland excelled for mean impact factor. Finland, the UK, and the Netherlands showed the highest scores for the ratio between scientific publications, number of inhabitants, and GPD. Our results are consistent with the view that small countries perform usually better than larger ones in terms of scientific rheumatological production. These data confirm the observations of Benzer et al concerning the overall medical publications in 1990. In that year, Israel, Sweden, and Switzerland had the highest scientific output per country population. In another study, the number of papers produced by a given country was related to the number of physicians. ${ }^{5}$ In this study, the UK was first with 0.37 publications per physician followed by Israel, Switzerland, Denmark, Finland, Sweden, and the Netherlands. Finally, Hausen et al $l^{6}$ evaluated scientific production according to the gross domestic expenditure for research in 1989. New Zealand, Denmark, Spain, Canada, and the Netherlands scored high in this ranking.

The reason why small countries have a higher scientific output than larger ones is not known. A better utilisation of resources and a higher percentage of the GPD assigned to research may be an explanation. Small nations may sometimes have a high scientific output because of clustering of specific diseases. An example is Finland, where rheumatological research is mainly oriented to reactive arthritis, a disease with high incidence in that country. ${ }^{7}$

We observed a very high dispersion of the keywords used in rheumatological journals. Only $2.1 \%$ of them was cited more than 10 times and $16.3 \%$ more than twice. This fact was mainly because of the use of different synonyms and only marginally because of 
misspelling. This problem does not only affect rheumatology. In fact, our data show that the percentage of keywords cited more than 10 times in dermatological or geriatrical journals in 1995 was $3.6 \%$ and $2.8 \%$, respectively. We believe that editors should encourage standardisation of keywords so that the retrieval of bibliographic information through computerised databases is facilitated. A standardised keyword system should include items such as field of research, disease and its localisation, methods used, and relevant drugs or biological agents.

A curious observation is that diseases of low incidence show a relatively high ranking of their relevant key words. ${ }^{8}$ Rheumatoid arthritis and systemic lupus erythematosus are still today the most frequently studied diseases, as in $1981 .{ }^{9}$ Among common diseases, osteoarthritis and fibromyalgia are important exceptions ranking at the third and fifth place, respectively, probably reflecting a change in trend. This fact is confirmed by the high mean impact factor (3.08) of papers with osteoarthritis as keyword. The ranking of drug related keywords highlights the continuous interest in methotrexate (56 citations) and is mostly in keeping with the list of drugs that are commonly used by rheumatologists in their daily practice.

In this study, only journals quoted as rheumatological were considered whereas many papers from rheumatological centres are published in other journals. This is an inherent bias for a complete review of the scientific production in rheumatology. Of course, the identification of rheumatological articles in other journals is far more complicated and was not attempted in this study. The two main problems are the spreading of keywords and the inaccurate reporting of author's addresses. We are developing a method to identify the scientific background of the authors by matching keywords, names of the authors and relevant institutions that could fill this gap.

No global representation of research output is in itself satisfactory because quality and practical relevance are difficult to evaluate. None the less, IF, a crude measure of the audience of a journal, is a fair indicator of the scientific relevance of a given paper. We feel that bibliometrics can help understand the trends of rheumatological research, evaluate the areas where more research efforts are needed, and improve the methods of distribution of resources.

The expert secretarial assistance of Mrs Mara Salvi is gratefully acknowledged.

1 Benzer A, Pomaroli A, Hauffe H, Schmutzard E. Geographical analysis of medical publications. Lancet 1993;341:247. Cal analysis of medical publications. Lancet 1993;341:247. Brussels: Eurostat, ECSC-EC-EAEC, 1996.

3 Ruiz MT, Alvarez-Dardet C, Vela P, Pascual E. Study designs and statistical methods in rheumatological journals: an international comparison. $\mathrm{Br} \mathrm{J}$ Rheumatol 1991;30:352-5.

4 Staab MA. Geography of medical publications. Lancet 1993;341:634.

5 Eldor J. Geography of medical publications. Lancet 1993;341:634.

6 Hausen A, Reibnegger G, Wachter H. Geography of medical publications. Lancet 1993;341:634.

7 Toivanen A, Toivanen P. Current trends in Finnish rheumatology. Br J Rheumatol 1996;35:489-91.

8 Williams GH, Rigby AS, Papageorgiou AC. Back to front? Examining research priorities in rheumatology. Br J Rheumatol 1992;31:193-6.

9 Dixon AstJ. Research is for now too. J Rheumatol Dixon AstJ. Rese. 